\section{Shock intensity effects in shuttle-box conditioning of guinea pigs 1}

RONALD G. RABEDEAU, San Jose State College, San Jose, Calif. 95114, and C. D. WEBSTER, Addiction Research Foundation. Toronto, Ont., Canada

Guinea pigs were given shuttlebox avoidance training with one of three different shock intensities. Low shock produced the most rapid acquisition and highest final performance. In a second session, $48 \mathrm{~h}$ after the first, there was a marked and immediate increase in performance of low and medium-shock animals. These results are attributed to the interference of performance $b y$ incompatible responses elicited bv high emotional arousal that dissipates with time after initial training.

Rats in a two-way shuttlebox typically avoid more frequently at low shock intensities than at high intensities (Moyer \& Korn, 1964; Levine, 1966). Webster, Brimer, \& Evonic (1965), however, found no relation between avoidance performance and shock intensity using guinea pigs. They did find, as others have (Evonic \& Brimer, 1967; Ireland, Hayes, \& Schaub, 1969), that few avoidance responses occurred in the initial training session. There is evidence that shows that, after failing to perform in the first session, guinea pigs show a remarkable and immediate increase in performance if retested $48 \mathrm{~h}$ or more later (Webster \& Rabedeau, 1964). To account for this "48-h effect," Webster and Rabedeau suggested that first-session performance was impaired by "emotional reactions" that dissipated in the interval between training sessions, permitting markedly improved second-session performance.

The purpose of the present study was to reexamine avoidance learning in guinea pigs as a function of shock intensity. It was expected that guinea pigs, like rats, would perform better with low shock than with high shock because there would be less interference with the instrumental response at low intensities. Animals were trained in two sessions in order to observe the effects of first- and second-session shock in tensity on the "48-h effect" noted above.

Fig. 1. Percentage avoidance responses for first-session shock groups during original learning in blocks of $\mathbf{1 0}$ trials and for the same groups in the second session in blocks of five trials. $N=39$ in each group. between 300 and $565 \mathrm{~g}$. scrambled shock source.

\section{SUBJECTS AND APPARATUS}

The Ss were 117 guinea pigs, weighing

The training apparatus was an automated shuttlebox, $30 \times 7 \times 6$ in. high. The top and front side of the box were made of clear plastic, the back and ends were unpainted plywood. The floor consisted of 60 stainless steel rods set $1 / 2$ in. apart. Two photo-conductive cells, one located $3 / 4$ in. from either side of the center line and $2 \frac{1}{4} \mathrm{in}$. above the floor of the box, permitted automated tracking of S's position in the box. Stimuli were presented and responses recorded with standard programming equipment. The $\mathrm{CS}$ was from a $24 . \mathrm{V}$ buzzer suspended $9 \%$ in. above the center line of the box. A Grason-Stadler Model $6070 \mathrm{~B}$ shock generator provided a

\section{DESIGN AND PROCEDURE}

The $117 \mathrm{Ss}$ were assigned randomly to three groups for initial training under three shock intensities. Each of these groups was then divided randomly into three subgroups and the animals were retrained under one of the shock intensities according to a 3 by 3 factorial design.

The shock intensities were the 1.3-, 3(as in Webster \& Rabedeau, 1964), and 6-mA dial settings of the Grason-Stadler shock generator. The low shock was about the lowest that produced efficient escape

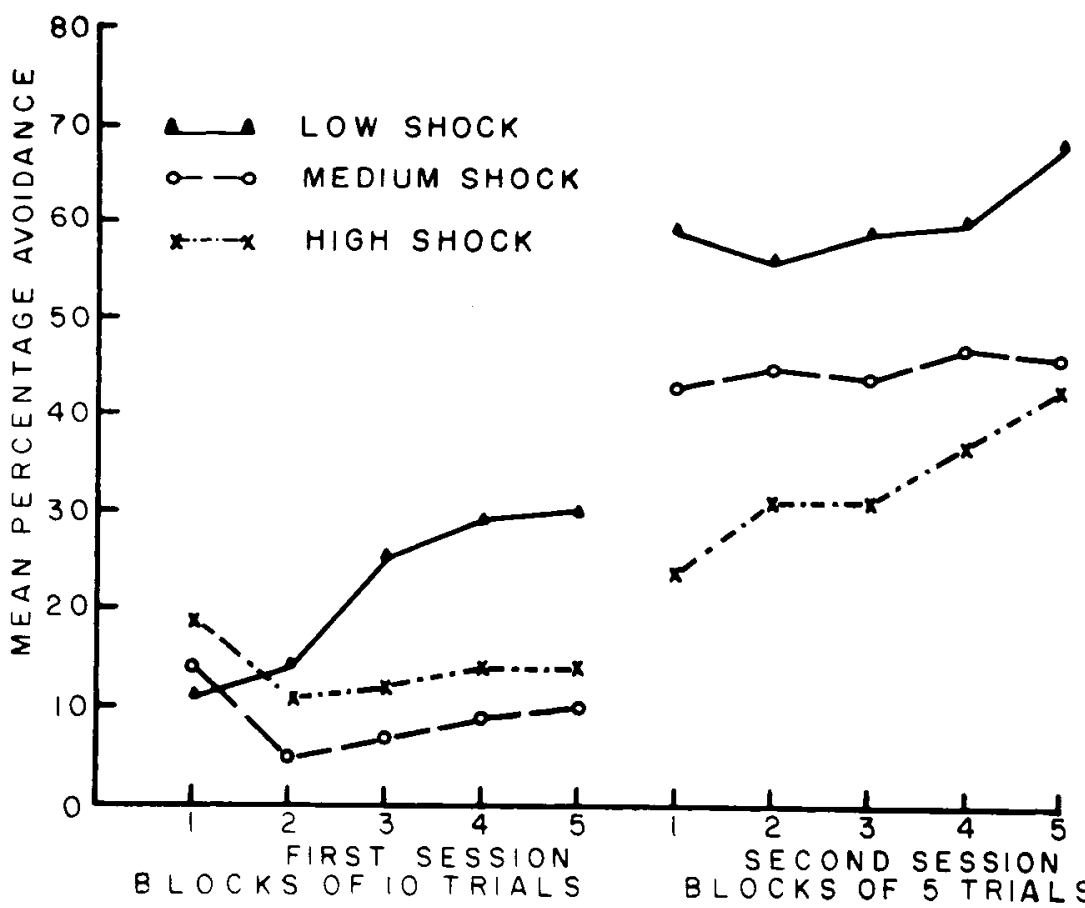

behavior in preliminary studies and the high shock was about the highest that could be administered repeatedly without injury to the Ss.

Except for the shock intensity, the procedure was the same for all groups. The first session consisted of a $10-\mathrm{min}$ adaptation period in the apparatus followed by 10 CS presentations. Following acclimatization to the CS, 50 delay conditioning trials, with a 10-sec CS-UCS interval and 1-min intertrial interval, were given. Both CS and UCS were terminated when the $S$ crossed the center line of the shuttlebox.

The second training session was given $48 \mathrm{~h}$ after the first and consisted of a $2-\mathrm{min}$ adaptation period followed by 25 avoidance-training trials.

\section{RESULTS}

The first-session results are shown in the left segments of Fig. 1. The low-shock group showed a definite improvement in performance over trials, while the mediumand high-shock groups improved very little. An analysis of variance on these data yielded a highly significant interaction between groups and trials ( $F=7.23$, $\mathrm{df}=8 / 456, \mathrm{p}<.01$ ), indicating a reliable difference in the slopes of the learning curves. The three groups also differed significantly in terms of the total number of avoidance responses ( $F=5.30$, $\mathrm{df}=2 / 114, \mathrm{p}<.01)$. A one-way analysis of variance on the last block of the 10 trials $(F=6.32, \quad \mathrm{df}=2 / 114, \quad \mathrm{p}<.01)$ and Tukey's gap test $(\mathrm{p}=.05)$ showed that the final performance of the low-shock group was reliably better than the other two 
Table 1

First-Session Escape Latencies in Seconds

\begin{tabular}{lcc} 
Group & $\begin{array}{c}\text { First Five } \\
\text { Trials }\end{array}$ & $\begin{array}{c}\text { Last Five } \\
\text { Trials }\end{array}$ \\
\hline Low & 1.52 & .72 \\
Medium & .60 & .54 \\
High & .25 & .39 \\
\hline
\end{tabular}

groups'. The medium- and high-shock groups did not differ significantly from one another.

Escape latencies for the first five and last five escape trials are shown in Table 1. Analyses of variance between the three groups on the first five escape trials $(\mathrm{F}=23.5, \mathrm{df}=2 / 114, \mathrm{p}<.01)$ and on the last five escape trials $(F=8.7, \mathrm{df}=2 / 114$, $\mathrm{p}<.01$ ) indicated a highly reliable inverse relation between shock intensity and escape latency. There was, however, a clear and significant tendency for the low-shock latencies to decrease $(t=4.24, d f=38$, $\mathrm{p}<.001)$ and for the high-shock latencies to increase $(\mathrm{t}=3.36, \mathrm{df}=38, \mathrm{p}<.01)$ from the first to the last block of five escape trials. The medium-shock-group latencies did not change significantly.

Most Ss made only one or two intertrial responses and these tended to be made early in training. There was no evidence for reliable group differences on this measure.

The curves for the same three groups (i.e., in terms of first-session shock intensity) are shown on the right of Fig. 1. The overall group differences were highly significant $(F=6.78, \mathrm{df}=2 / 108, \mathrm{p}<.01)$.

The increase in performance from the last 10 trials of the first session to the first 5 trials of the second session was $32 \%$, $32 \%$, and $10 \%$, respectively, for the low-, medium-, and high-shock groups. An analysis of variance performed on these change scores $(F=7.76, \quad$ of $=2 / 114$, $\mathrm{p}<.01)$ indicated a reliably greater improvement for the low and medium groups in comparison to the high-shock group.

No systematic effect due to second-session shock intensity was observed and the differences did not approach significance $(F<1)$. The separate curves for second-session shock intensity have been combined in Fig. 1 .

\section{DISCUSSION}

Guinea pigs trained with low shock improved at a greater rate and reached a higher final level of performance than did animals trained under medium or high shock. In this respect, guinea pigs appear to behave like rats (Moyer \& Korn, 1964 Levine, 1966). It is not certain why Webster et al (1965) failed to find this relation, but it is possible that their low shock ( $0.4 \mathrm{~mA}$, also from a Grason-Stadler 6070B shock generator), which should have produced the best performance, was simply too low to motivate learning adequately. Our preliminary work indicated that $1.5 \mathrm{~mA}$ was about the lowest shock intensity that would produce prompt and reliable escape behavior. (Guinea pigs appear to be very much less sensitive to foot shock than do rats.)

In addition to differences in initial performance, the present study also demonstrated the sharp increase in avoidance level following a 48 -h rest as originally reported by Webster \& Rabedeau (1964). Of interest here is the fact that the intersession improvement was greater for the first-session low and medium groups than for the first-session high group and that it was independent of second-session shock intensity. Thus, the factor that interferes with performance does not disappear after $48 \mathrm{~h}$ if the initial training is conducted with very high shock. Because of the relatively high level of avoidance responding of the low and medium groups in the second session, these animals received relatively few shocks. This may account for the fact that the second-session performance did not relate to second-session shock. The same explanation hardly applies to high-shock Ss. Their performance may have been so suppressed that recovery was not possible.

In order to account for the main results of the present study, the following suggestions are made. Massed shocks, especially intense shocks, administered at the beginning of training, induce a state of increased emotional arousal that, in turn, elicits overt responses (e.g., crouching and freezing) incompatible with tho instrumental response. This contention is supported not only by the greater avoidance level on the part of low-shock Ss but also by the fact that escape latencies increased over trials for the high-shock $S$ s and decreased for low-shock Ss. That is, high-shock escape performance deteriorated while low-shock performance improved with training. Presumably. second-session avoidance performance is improved because emotional arousal declines and consequently fewer incompatible responses are elicited after a sufficiently long rest. The continued poor performance of animals originally trained with high shock may be the result of a longer interval required for return to normal arousal level or to conditioning of incompatible responses to apparatus cues during the first session.

REFERENCES

EVONIC, I. N., \& BRIMER, C. J. Effect of variable temporal parameters in avoidance conditioning of the guinea pig. Journal of Comparative \& Physiological Psychology, 1967, 63, 536-538.

IRELAND, L. C., HAYES, W. N., \& SCHAUB, R. $E$. The effects of bilateral hippocampal lesions on two-way active avoidance in the guinea pig. Psychonomic Science, 1969, 14, 249-250.

LEVINE, S. UCS intensity and avoidance learning. Joumal of Experimental Psychology, $1966,71,163-164$.

MOYER, K. E., \& KORN, J. H. Effect of UCS intensity on the acquisition and extinction of an avoidance response. Journal of Experimental Psychology, 1964, 67, 352-359. WEBSTER, C. D., BRIMER, C. J., \& EVONIC, I. N. Factors affecting intersession facilitation of avoidance in guinea-pigs. Psychonomic Science, 1965, 3, 291-292.

WEBSTER, C. D., \& RABEDEAU, R. G. The effect of intersession interval in shuttle-box conditioning of the guinea-pig. Psychonomic Science, 1964, 1, 73-74. NOTE

1. This research was supported by National Research Council of Canada Grant APA 68 and was conducted at Queen's University, Kingston, Ontario. 